\title{
Parasitology, Other
}

National Cancer Institute

\section{Source}

National Cancer Institute. Parasitology, Other. NCI Thesaurus. Code C19294.

This term is used as a form filler when there is no appropriate Parasitology term available. 